\title{
Foreword by the Right Honourable Lord Gill
}

For twenty-seven years Professor McManus, in his teaching and in his writings, has advanced the study of environmental law. During that time the subject has grown in importance and complexity. The national and international legislation by which the United Kingdom is bound has set higher environmental standards and more effective means of enforcing them than ever before. Nevertheless deficiencies remain and the need to deal with them is increasingly urgent.

Professor McManus's work gives us a conspectus of the common law and the statutory law by which our society tries to protect present and future generations against the destruction of the earth. It has the particular merit of setting the development of each aspect of the law in its historical context.

This will be an invaluable guide for practitioners and academics and for those in central and local government and in the planning and environmental professions who deal with problems of pollution and waste management in their everyday work. I have read the manuscript of this work with great pleasure and profit. I congratulate Professor McManus on having produced a valuable and timely contribution to Scottish legal literature. I hope that it will become a standard work of reference.

Brian Gill August 2015 